\title{
Training Programs Evaluation for Educational Supervisors in Oman
}

\author{
Zayid Ali Khalfan AL-Hosni \\ Faculty of Education, University of Malaya, Kuala Lumpur, Malaysia \\ Kazi Enamul Hoque \\ (Corresponding Author) \\ Faculty of Education, University of Malaya, Kuala Lumpur, Malaysia \\ Abdul Rahman Idris \\ Faculty of Education, University of Malaya, Kuala Lumpur, Malaysia \\ Abdul Jalil Othman \\ Faculty of Education, University of Malaya, Kuala Lumpur, Malaysia
}

Accepted: August 13, 2013 Published: Sep 06, 2013

Doi:10.5296/ijld.v3i4.4244 URL: http://dx.doi.org/10.5296/ijld.v3i4.4244

\begin{abstract}
In today's organizations training is one of the major parts of human resource development (HRD), but training is incomplete until and unless evaluation has taken place, however several previous studies in universal context shows that there is gap in evaluation training programs. In line with this aim, this study had the effort to investigate the perceptions of educational supervisors (ES) concerning current practice in evaluating training programs (ETP) of ES by Ministry of Education (MOE) in Oman. This paper adopted qualitative approach; using multiple- case study design in which data were collected through interviews, also observations and documents review to supplement interview data. The participants in this study were training providers, training evaluators, trainers, direct superiors, and trainees. Data revealed that respondents expressed different views regarding current practice in ETP of ES by MOE, Oman. Most of the interviewees' reflected that existing ETP still not implemented to its full capacity and the appeared that evaluation faced many challenges to get planning, short-terms, and long-terms evaluation resulted; The participants expressed variety recommendations and suggestions to overcome the current weakness and the shortcoming of evaluation performance practice by MOE.
\end{abstract}

Key Words: Training programs, Educational supervisors, Evaluation, Oman

\subsection{Background}

Current conditions necessitate the need for specialized training capable of facing challenges. Training to the universal organizations is one of the major parts of human resource development (HRD). Aminuddin(2001) claim that training is an investment(p. 4).Goldstein and Ford (2002, p. 1) have specifically defined training as "the systematic acquisition of skills, rules, concepts, or attitudes that result in improved performance in another environment". Likewise, Sims (1993, p. 605) sees training as "a step toward improving job performance and/or organizational effectiveness". Smith (2002) confirmed the "importance of off-the-job training as a supplement for workplace learning"(p. 431). 
In general, to ensure HRD goals are achieved, a HRD program should be des igned according to these phases: training needs analysis, design ("define objectives, develop lesson plan \& materials, select trainer and methods, schedule the program"), implementation, and evaluation (Werner \& DeSimone, 2009, p. 26). Sims (1993) asserts that "training process is not complete until and unless evaluation has taken place, for it is evaluation which informs training and gives it meaning" (p. 591). Goldstein and Ford (2002) have put forth that "an evaluation will not solve all training problems, but it is an important step forward" (p. 141). In simple terms we can say that "evaluation is an essential means for finding out and acting on what is going right and wrong" (Stufflebeam \& Shinkfield, 2007, p. 30). As stated by Werner and DeSimone (2009), evaluation builds credibility; it shows whether a training program has fulfilled its objectives. The purpose of undertaking evaluation been asserted by many researcher, Kirkpatrick(2006) highlights three main reasons for evaluation: (a) to justify the existence and budget of the training department by showing how it contributes to organizational objectives and goals; (b) to decide whether to continue or discontinue training programs; and (c) to gain information on how to improve future training programs. Bramley (1991) similarly views evaluation as important to the training cycle and that it has a significant role in providing feedback on whether the needs originally identified, both at organizational and individual level, have been met" (p. 87). Phillips \& Stone (2002, p. 2) asserts that "there must be a comprehensive measurement and evaluation process to capture the contributions of human resource development and establish accountability". Previously, Phillips (1997, pp. 36-38) stated that evaluation can help to: 1 ) determine the attainment of program objectives; 2 ) determine the efficiency (the strengths and weaknesses) of HRD programs and activities which can be used to make further or future improvements;3) identify if the cost of an HRD program has paid off; 4) decide prospective participants; 5) verify tests, cases, and exercises to ensure that they are able to measure knowled ge, skills, and abilities (KSA); 6) identify which participants benefited the most from the program or otherwise where the information can be used to decide if a participant should be promoted, transferred, retained, and so on; 7) remind participants on the KSA that have been acquired and how should they apply on the job; 8) gather data to develop future programs' marketing strategy such as determining the rationale of attending a program, the decision to attend a program, and announcement of future programs; 9) determine if training is needed or necessary to solve a specific problem; and 10) establish a database to assist management in decision making.

The decision not to undertake evaluation will result in the ineffectiveness of current and future training programs. Some of the consequences of not evaluating, as spelled out by Rae (1999), among others are: the impossibility of assessing trainers, not knowing learners' reactions, inability to assess learning transfer, unawareness of success by sponsors, and impossibility of valid responses. Thus, evaluation is needed to make HRD work better and may turn training failures into success (Junaidah, 2006:86, Brinkerhoff, 1987).

Rae (1999) listed the reasons for underemphasizing evaluation or not undertaking evaluation seriously: a) no strong belief in evaluating training programs; b) trainer's ignorance; c) evaluation only refers to training on definite, measurable end prod uct like computer training; d) uncertainty of whose or which department's job responsibility; e) evaluation was not an issue when training programs were arranged; f) evaluating is so much time consuming and would interfere with training's quality time; and g) evaluation is only about handing out questionnaires at the end of the course.

All the reasons for not undertaking evaluations above may result in dire consequences. Rae (1999) mentions that underemphasizing and not undertaking evaluation may lead to consequences such as: a) impossibility of doing trainer self-assessment; b) impossibility of doing assessment on trainers; c) inability to assess training design; d) unknown learners' reactions/learning; e) inability of learners to see changes in learning; f) inability to assess 
learning transfer; g) unawareness of success by senior sponsors; and h) impossibility of valid responses.

The training program evaluation method and processes could be considered to be pioneered by Donald Kirkpatrick in the early 1960s. Only then, since the last third of the twentieth century has the field of evaluation been regarded as a distinct profession "the last third of the twentieth century" (Stufflebeam \& Shinkfield, 2007, p. 31).Even though the evaluation phase is undoubtedly important Werner and DeSimone (2009) claim that it is an "often underemphasized activity". Underemphasizing evaluation perhaps is a never ending issue since the field of evaluation was given attention in the 1970s. The field of evaluation, in general, has been made a distinct profession since the 1970s. Nevertheless, hitherto, most organizations regard this field as taxing and it is often ignored. Sims (1993) citing Galagan (1983) states that through a survey done, more than one-third of the American Society of Training and Development (ASTD) members responded that evaluation was the hardest aspect of work. Back in 1993, Sims observed that few reports of actual program evaluation have been published; compared to the number of training programs, few evaluations have been conducted (p. 591). Sims is parallel to Werner and DeSimone's (2009) training and HRD process model where evaluation is set in the final phase of the training process, preceded by needs assessment phase, design phase, and implementation phase. In substantiating this claim, Junaidah (2006, p. 184) stated that "in many organizations evaluation of training either is ignored or is approached in an unconvincing or an unprofessional manner".

However, to date, evaluation of the training programs are not given emphasis. Goldstein and Ford (2002) stated that there has been a substantial number of organizations which undertook program evaluation. Unfortunately, they further argue that, "most of the evaluations focused on trainee reactions to the program rather than determining whether learning had taken place and job performance had been positively impacted"(p. 138). This assertion shows that the practices of evaluating are most of the time unsystematic and based on simple means and the evaluation results are not the ;foremost priority of the organization (Junaidah, 2006; Russ-Eft \& Preskill, 2001). Evaluation is also overlooked or "not implemented to its full capacity" (Wang \& Wilcox, 2006). Even though there are numerous researchers in training program evaluation, most of them measure perceptions and level of use for example, Phillips (2003), Al-Athari \& Zairi (2002), Green (2004) and Al-Hatmi (2009).

Generally according to Galanou and Priporas(2009) ), citing Kaplan and Norton (1996) claim also that "training programs generally lack practicability and their impact has not been systematically evaluated" makes several important points" (p. 235). They further states that to achieve the best quality results in investigation the impact of training programs that more research is needed in order to move away from the unplanned and poorly idea conceived(p. 235). Similar to Eseryel (2002), is also citing Carnevale \& Schulz(1990), Holcomb (1993), McMahon \& Carter (1990), and Rossi et al.(1979) claim that "there is evidence that evaluations of training programs are often inconsistent or missing"(p. 4).

The Omani society, like other modern societies, is continuous effort in developing its human resource could be seen through its 2020 economic vision where the development of human resource is regarded as one of its primary aims to achieve its Vision. The national vision is stated as: "Development of human resources, and upgrading Omanis skills and competencies to keep abreast with technological progress; to manage the dynamics of this progress in a highly efficient way; and to face the ever-changing domestic and global conditions" (MONE portal, Chapter 2, p. 1).

Therefore, Oman always put HRD as an important division to improve its educational system and to meet the new century's challenges, therefore Oman, in its initial stage of building its human resources had issued an education philosophy in 1978. One of its educational goals is to "accomplish a comprehensive development for the Omani society" is to "train manpower 
required for work and production" (MOE, Philosophy of Education, 2004, pp. 46-48). For this purpose, education will play a vital role to prepare the citizens of Oman to fill the labour market which will then qualitatively and quantitatively achieve its economic development.

Presently, the MOE, Oman in professionally developing the skills and knowledge of its staff, teachers and school administrators has provided and organized "training course, lectures, workshop, seminars, symposiums, summer activities and projects" (MOE, EF A, 2007, p. 102). The purpose of establishment all this training methods is to provide continuous learning opportunities at "various levels in the MOE, local authorities and schools" so that changes in education could occur (MOE, National Report, 2004, p. 10). As stated in the 2004 National Report, the main responsibilities of the MOE are to "plan, implement and follow-up in-service training opportunities according to the MOE's reform plan; and duties".

The MOE, Oman continuously conducts short-term training programs for employees in different specializations and fields. Since the MOE's reformation in 1997, the training programs field is obligated to include the following: (a) follow up and evaluate the implementation of training programs, (b) follow up and evaluate trainees' application after every training program session, (c) the MOE organization, department, and school performance return from training program and (d) evaluate annual training program plans based the training program provided type in achieving the targeting the general goals of the ministry.

In line also many of the studies in the local context in Oman, finds that the existing evaluation of training program in public sector still not satisfactory; Al-Khalili(2003) stated that the quality of training does not meet the expectation of the trainees' needs, and training programs are conducted in a very short span of time that it is not sufficient for the trainees to assimilate training subject(p. 61). Parell to Al Khalili as a local studies Al Hanshi(2004) also claim that the training in Oman facing many challenges, such as, there is limited and lack in training quality in both public and private sectors. He further stated that should do research about training fault reasons and develop HR professional (pp. 64-65). Similar to the previous local studies' findings Al-Nabhani (2007) also as local study share same opinion by stated that there are shortcomings in evaluating training results in the current MOE, Oman training program. Her study also shows that the training plans of the ministry, and prepare the finally evaluation reports are hardly followed any systematic approach to training program evaluation, and the evaluations process were done merely to see participants' satisfaction with the programs, and mostly without feedback of the sequences of the training program in terms of its success in achieving the targeted aims. Also according to Al Amri (2008) indicated that the "interest of educational supervisors in training and professional development was being recorded as being slow".

Therefore this study attempts to fill the research gap in the training program evaluation field as most researches measure perceptions and level of use for example: Phillips (2003), Al- Athari \& Zairi (2002), Green (2004) and Al-Hatmi (2009). The current study however looks beyond that to see if training programs are meaningful (Lingham, Richley, \& Rezania, 2006), not necessarily in monetary terms, but to see if there are any changes or improvement on personnel, for example changes in attitude or behavior as changes in individuals indirectly will create changes in an organization. This As far as the researcher is concerned, the MOE, even though it has executed some form of evaluation training program, has not exercised any systematic form of evaluation model. Since most evaluation training program approaches cater to businesses and for-profit organizations, the researcher believes there is a need to develop an evaluation training program approach that suits the culture of a public sector or government service. Presently, very few researches have been done on the public sector other than the studies by Al-Hatmi (2009), Phillips (2003) and Sims (1993). It is hoped that the results of the current study could add to the existing literature in the field. Therefore, through this study, it is 
hoped that the wide examination and application of the literature in the field of training program evaluation according to the implementing evaluation levels in this study, and the findings of this research are going to contribute to the body of research in human resource development in general and performance evaluation in particular, especially in the training program evaluation context.

Consequently, regarding to all previous local studies resulted shows the importance to investigate the implementation of the existing evaluation training program. Therefore, this paper aims to find and looked into relevant participants' perception regarding the practice in evaluating the training programs of ES which are carried out by the MOE, Oman, also its aim to identify some ways in order to help the MOE to improve the current evaluation of the training programs of ES.

1.1 Research Question:

Based on the objective outlined above, research questions are formulated which are:

1- What are the respondents' perceptions regarding the current evaluation of the training programs of ES?

2- How can the current evaluation of the training programs of ES be improved?

\subsection{Methodology}

In the circumstances of the current study and due to its aims, qualitative methodology was chosen to adopt, since this study was interested in obtaining an in-depth picture of the evaluation ES training programs by investigating the relevant participants' views regarding current process of the evaluating of ES training programs of the MOE in term of impact on several levels of evaluation including planning, design, satisfaction, and learning of trainees. It was also designed to carry out evaluation in terms of the training program long term effect on the attitude and behavior of the ES as training participants, also this study investigated the worth outcomes or it significance of evaluation ES training programs on the performance of trainees organization. Finally, this present study also investigated any suggestions or recommendations for developing and overcoming issues in the current evaluating ES programs of the MOE. In this study multiple case study design was used, including a cross-site analysis. Researcher adopted purposeful sampling for selection site and training programs. This study gathered data from three selected training programs targeted to train the ES trainees, and centrally held in the headquarters of MOE within the 2011 Official Training Programs Plan. For the purpose of this study, the case study unite was the relevant participants', the involved participants: trainers and trainees were selected from those three training programs, also the training evaluators, training providers, and direct superiors as other participants were selected according to their current official job responsibility in MOE.

\subsection{Instruments: Validity and Reliability}

For the current study, the instruments selected to be used in executing evaluations and collecting related data are: first the one-on-one semi-structured intervie ws as the dominant and the main source data collecting tool, whereas direct observations and documents analysis will be used employed to support and supplement interview data. To ovoid leading and dichotomous question, the researcher used open-ended questions in the interview, and during these process the researcher took down filed notes and recorded the interview, so that none of the information was missed. For observation, the researcher used direct observation during visit the site, while observing, the researcher took down filed notes. Finally, the researcher attempt to review the obtained documents and relevant to the implementation of current evaluation training programs. This current research as qualitative case studies be employed these multiple instruments as procedure and strategies was able that could reached high level of validity and reliability of the applied instruments, since the concern of validity and reliability 
contribute to reach results that are believable and trustworthy, since the researcher was able to triangulate data from different source and strengthen the research approach, and give more strength interview data during investigation at the site.

In this study also other ways were used to ensure validity and reliability of used instruments. For the validity these comprised that, this current study acquired assistance and opinions from experts in the field. This current study was also meticulous in ensuring that each item of the instrument was devoid of misunderstanding and vagueness. At the actual event of doing evaluation, all data collected were reviewed and verified by the trainers and superiors in the MOE before an analysis and interpretation was communicated. From time to time, interview questions were revised and refined. As for the documents for review, as far as this study was concerned, they were valid as they were obtained from the MOE of Oman and not from external sources.

Furthermore the prolonged engagement and meeting were reassured by this current study through his visiting and arranging meeting of about six months at the training program sites, launched on $29^{\text {th }}$ January 2011, and ending in November 2011. The researcher during this period of time was attended to the training hall, and involved in all the training events related to the selected ES training programs.

Finally this current study has chosen participants from different categories such as training providers, training evaluators, trainers, and trainees to cross check the information and thus to ensure reliability of data.

Naturally, in the current study, the collected data were analyzed according to the study's research questions. Nevertheless, the process of analyzing and interpreting data was continuous as this current study discovered new information every now and then. For that reason, the current study followed closely, if not all, the seven-phase analysis procedure suggested by Marshall and Rossman (2006, p. 156), namely: "(1) organize the data, (2) immerse in the data, (3) generate categories and themes, (4) code the data, (5) offer interpretations through analytic memos, (6) search for alternative understandings, and (7) write the report or other format for presenting the study."

3.0 Findings

Three training programs were chosen purposefully and three were five respondents were interviewed. They are identified in this study as TP (Training Provider), TE (Training Evaluator), T ( Trainer), TR ( Trainee), and DS ( Direct Superior).

3.1 Participant's perception regarding implementation current evaluation:

Regarding question one "What are the respondents' perceptions regarding the current evaluation of the training programs of ES?" The four themes that emerged from the analysis of the interviews with the participants are as follows: targeted evaluation aims, carryout evaluation process time, applied tools and methods, and significance of the evaluation consequence. The following extracts elaborated these themes.

\subsubsection{Targeted evaluation aims (Theme 1)}

The evaluation targeted aims based to the official structured of the ministry currently cover three evaluation phases included several evaluation levels. TE describes as follows:

In the ministry currently the evaluation process can be classified to three evaluation phases into ETP of ES. The first phase to evaluate training plan before conducting training. The second phase to evaluate the short-term results of training, and its practice during implementing training to evaluate design, satisfaction, and learning levels. The final phase concerning to evaluate the long-term impact of the training, and its carry out after training held, and its process practiced in work context to evaluate the knowledge and skills transferred level and the organization resulted level 
Furthermore TE elaborated that evaluation process currently limited since it didn't cover all of the previous evaluation levels. He stated:

What I relies during implementation evaluation process during conducting training for ES that the most focused aspects are to evaluate design level, and the attended trainees satisfaction level, and there is less focus on finding out the trainees' interest to learn, this the obvious evaluation process but beyond to evaluate learning level are almost ignoring

In addition, $\mathrm{T}$ support the participant $\mathrm{TE}$ idea regarding the implementation of current evaluation, when asked here opinion in the current practice of evaluation the long-term impacted of the ES training program by the ministry. She replied:

The existing evaluation in my opinion not reach systematically the long term result of ES training programs, I think need to extend the targeted evaluation implementation aims and process to evaluate the transfer of the knowledge and skills, and the organization costs and benefited which currently rarely be practice

In other hand the TR revealed that the ministry interest to practice the evaluation of knowledge and skills transfer level in case the ES employees going to promote. In her expression said:

Whether trainee going to promote for a new title job in the ministry in this case the evaluation trainees' application at the work context going to be more focused in the current evaluation process

\subsubsection{Carryout evaluation process time (Theme 2)}

Participant DS commented that there is overlapping in practice time of evaluation process either during conducting training or to evaluate the long result at the work context. His complained illustrates in the following two extracts:

the carryout time of evaluation process going in an appropriate time during conducting training program, its undefined time whether to evaluate design, satisfaction, and learning, in my opininon the evaluation training not easy task its need well prepare and consuming long time to practice

He added:

Carrying out of practice to evaluate knowledge and skill transfer level is hardly done at a set time to be evaluated, and mostly practiced in unsystematic scheduled time according to the evaluators' visits, since these visits are related to the availability of provided transportation, a lot of factors impacted in term carry out evaluation process, and its influenced in the evaluation gained results

\subsubsection{Applied tool and methods (Theme 3)}

This study finds that the current used different tools and applied methods in evaluation implementation. The TP asserted that some of applied tools are more focused than the other and sometime its unsuitable to evaluate learning level. His claimed:

What I recognize that the emphasis on evaluating trainees' learning to employ presentation activities as major tool during and in the final conduct of the training program, but to ask the trainees to sit for final test to evaluate their learning was not preferred generally by the stakeholders, trainers, and the trainees in the current process into ETP of ES

In addition, also the TP revealed the reasons that current evaluation not applied the writing test in the evaluation of ES trainees learning level

the test in term in applying it not that much wanted and less employ because of many reasons driving this trend in the ES training programs like the age of ES attended 
trainees, position job, and difficult to prepare the test and later make the correction and get the final test marks since of the number of the trainees and the limited days of training event

Beside that the participant TE data revealed that some of evaluation tools need to rebuild. She claimed:

you can find that some of the included items with evaluation tools are not clear in meaning, and could carry several interpretations when written as the response since its broad or general words used, so that the feedback will be based as identified by the respondent during practicing the evaluation which will lead to different evaluation outcomes in the current process

3.1.4 Significance of the evaluation consequence (Theme 4)

In general according to the participants' views that currently there is less value of evaluation conclusion outcomes, since it mostly lacking in appear the evaluation sequences resulted. In the following an instance were given by involved interviewees. DS expressed that evaluation finally evaluation reports should address the reality resulted by saying:

Evaluation consequence process should address and appear the reality of implementation results, now it publish under broad and widely words, with pictures and number of training program and trainers, and trainees .. in sample word its add nothing

In addition, Participant DS revealed that there is the less significance of the current evaluation results indicates that its not presented all of the evaluation levels. He stated:

The current evaluation of organization costs and benefits level is seldom reached, since it related to overall goals of the ministry, and it is also difficult to find indictors to approve the result of this evaluation level.

Participant TE support the previous ides, and he stated:

The evaluation sequence conclusion resulted through the evaluation level phases mostly showed they were divided between evaluation short-term levels and the evaluation long term levels, and also exhibited weak link between the resulted outcomes between them.

He added:

The most of the published evaluation reports are not clear, since they carry broad meaning; also mostly the presented evaluation information in general statements; and focusing more in quantitative data such as numbers, percentages, and figures.

3.2 Recommendations for improving the implementation current evaluation

Concerning research question two "How can the current evaluation of the training programs of ES be improved?" The three themes that emerged from the analysis of the interviews with the participants are as follows: active the school context role, applying new evaluation approaches, and develop the qualification of evaluation requirements. The following extracts discussed these themes.

The almost of participant revealed different suggestions deal with overcoming the weakness, disadvantages principles, and shortcomings regarding the current evaluation practice. An example taken from the interview data collected from participants during conducting this study expressed how can achieved their recommendations by MOE.

3.2.1 Activate the school context roles (Theme 1)

The majority of the respondents interviewed had highly recommending to improve the current practice of evaluation training programs of ES there is a need for more activation of the school roles, and specifically in terms of evaluating the long-term levels. The participants were suggested different ways to be practiced and achieved within the school level. In the following 
extracts an example were given by respondents. The respondent TR expres sed that the training evaluation can be process through ES visits to the school during they practicing their work, TR typically said:

The current evaluation training process should be implemented through invest the educational supervisor school visits by evaluating their practicing and whether they transfer the gained knowledge and skills in the reality with the teachers in the school context

The participant TP suggested other way to develop the evaluation by link between the evaluation practice of ES job performance and the transferred of the knowledge and skills of the attended training program, and the both evaluation can be performed during the ES visiting and practicing their work at school level, and said:

In my thinking there is in fact strongly relation between the school and the ES work duties since most of this duties perform within the school, so of that it easy to link between the ES evaluation for job performance and the evaluation regarding knowledge and skills transferred from the attended training program, the school is the nature place to practice and evaluate this long impact of the training

T revealed other suggestion to be implemented be adopted long-term evaluation in the school level. In her expression, T said:

Contribution implement the process of the long-term evaluation levels based to the school level, since the long time I though enough to get deep evaluation specifically for long impact of the training programs in the ES and this practice compeer with practice at the school.

The participant TR has support the T idea regarding the applying long term evaluation for ES trainees, TR asserted that:

To achieve it the ministry now not later think to adopt long term evaluation within several training courses or within an academic year into ETP of ES, and the requirement activities should practice and evaluate within the school context

3.2.2 Applying new evaluation approaches (Theme 2)

The second type of recommendations made by the respondents are that the MOE should think to apply either modern or practical approach in the implementation evaluating of the current practice. In their respondents views this can get by employed the internet as modern method in evaluation training program purpose. In his expression, participant TE said:

Recently because of the widely users of the website for different purposes, I think its true decision whether the ministry going taken this step forward be utilized the internet website service into ETP of ES,

In addition, TP confirmed the previous idea regarding the role of the internet in improve the implementation. He stated:

Now days most of the people able to access to the internet and getting a widely of data and information, I believe that using the internet will going to solve different issues facing the ministry currently in term it implementing into evaluation process of the training programs,

Furthermore, he complained:

The evaluation through the internet sure will assist to accomplishment the evaluation training program targeted, also its able to keep in contact with the attended trainees at the work context and this will assist to evaluate them, and also it sure going to save the spend mony in term carry out evaluation

In addition, DS claimed that the ministry needs to establish independent department to take the role in in implementation evaluation process. He expressed that: 
To come over many of the problems that the evaluation faced now, the ministry have to establish independent institution into ETP, so it will be out of the pressure and the other factor which could threaten the impact and the result through the evaluation process 3.2.3 Developing the qualification of the implementation evaluation (Theme 3 )

The finally suggestion by the involved participants related to develop the qualification of the implementation evaluation requirements of the current process. Participant TE considered that to improve the practicing of evaluation that through providing specialist training in the evaluation field. He stated:

The evaluators stuff need more to qualify by improve their knowledge and skills in perform evaluation process, since currently their skills limited in the evaluation filed

In addition, TE revealed that, the ministry need to extend the capacity of the administrative requirements. He complained:

The evaluation of ES training programs claim to open other evaluation sections, and this requirement will need to employ other staff in the department since the number of evaluation section and employees currently limited

\subsection{Discussion}

4.1 participant's perception regarding implementation current evaluation

4.1.1 Targeted evaluation aims (Theme 1)

The current implementation evaluation targeted aims suppose currently cover three evaluation phases included several evaluation levels. This finding is similar to the finding of (Werner \& DeSimone, 2009) as they stated that to ensure HRD goals are achieved, a HRD program should be designed according to these phases: training needs analysis, design ("define objectives, develop lesson plan \& materials, select trainer and methods, schedule the program"), implementation, and evaluation.

The most of the participants shows that the most focused part in current evaluation process during conducting training program to evaluate the training program design, also to evaluate the trainees satisfaction or reaction toward the attended training, and to evaluate beyond that is almost ignored such as evaluate the attended trainees learning level. In line with this, the findings of Kirkpatrick (2006) showed that most companies use reaction sheets at the end of training programs but have not gone beyond that in evaluating.

According to Kirkpatrick (2006) who stated when applying his four-level framework that reaction, as the name implies, measures how participants of training react to the program; in other words, it measures customer satisfaction (p. 27), and has stressed several important advantages of this evaluation level that "it is important not only to get a reaction but to get a positive reaction as the future of a program depends on positive reaction. In addition, if participants do not react favorably, they probably will not be motivated to learn" (p. 22). Also according to Kirkpatrick (2006) as he exposed when evaluating learning, that there is three general questions are often brought up to determine if learning has taken place: "what knowledge was learned?; what skills were developed or improved?; and what attitudes were changed?".

The participants in their views added that there is carrying out of practice to evaluate knowledge and skill transfer level currently is hardly done at a set time to be evaluated, and mostly practiced in unsystematic scheduled time according to the evaluators' visits, since these visits are related to the availability of provided transportation in the ministry. Also this study finds that most interviewees' superiors observed that in terms of the trainee going to promote for a new title job in the ministry in this case the evaluation trainees' application at the work context going to be more focused in the current evaluation process, and a specific evaluation form will be used for this purpose. This finding is aligned to the findings of Philips (1997)who 
stated that the evaluation information can be used to decide if participant should be promoted, transferred, retained, and so on.

According to Phillips (1997) who exposed that the on-the-job application of knowledge and skills are to be evaluated four months after program. Junaidah (2006), who stated that the purpose of the training evaluation to "identify the program's strengths and weaknesses, and this includes determining if transfer of training to the job is occurring"(p. 186).

The current evaluation of organization costs and benefits level in the ministry is seldom reached, since it related to overall goals of the ministry, and it is also difficult to find indictors to approve the result of this evaluation levels. According to Junaidah (2006), as she asserted that one of the purpose of training evaluation "to determine the financial benefits and costs of the program"(p. 186 ) also accord ing to Lingham, Richley, \& Rezania(2006) as they asserted regarding meaningful of implement evaluation training are not necessarily in monetary terms, but to see if there are any changes or improvement on personnel, for example changes in attitude or behavior as changes in individuals indirectly will create changes in an organization. 4.1.2 Carryout evaluation time (Theme 2)

The Participant DS claimed that there is overlapping in practice time of evaluation process either during conducting training or to evaluate the long result at the work context. This finding is similar to the findings of Junaidah (2006) and also supported by Russ-Eft and Preskill (2011) as they claimed that the practices of evaluating are most of the time unsystematic and based on simple means and the evaluation results are not the foremost priority of the organization. According to Werner and DeSimone (2009) as they listed the more frequently reasons why evaluation is ignored; and of this reason is because evaluating is not an easy process and it is time, resources, and expertise consuming; therefore it is something that the HRD personnel are unwilling to exercise. ). Also according to Wills (1993) who mentioned that "another time evaluation is required when there has been a significant change in the organization, or when the course is due to be revised or replaced by a new course", "ideally evaluation of training should occur annually when the organization is assessing the success of its business plan" (p. 240).

4.1.3 Applied tool and methods (Theme 3)

This study finds that the current evaluation practice focused in used at specific tools, and this because its more preferred than other tool such as to ask the trainees to prepare a presentation activate is more preferred than ask the trainees to set to the test in term evaluate learning level. Also this study finds that the criteria of evaluation applied tools and methods since it created in broad and unclear statement so of that need to be developed by review and be rebuilt under specific standard.

\subsubsection{Significance of the evaluation consequence (Theme 4)}

The majority of the respondent revealed that there is less value of evaluation conclusion outcomes and the evaluation resulted or sequences didn't address the reality situation of implementation evaluation. This finding is in line with the finding of Al-Nabhani(2007) stated that there are shortcomings in evaluating training results in the current MOE training program, and prepare the finally evaluation reports are hardly followed any systematic approach to training program evaluation, and the evaluations process were done merely to see participants' satisfaction with the programs, and mostly without feedback of the sequences of the training program in terms of its success in achieving the targeted aims. Parallel to this finding the findings of Wang \& Wilcox (2006) they asserted that in the public sector evaluation is also overlooked or "not implemented to its full capacity".

They participants list many reason of that since the current result of evaluation in ministry created in broad and general words, focus more in pictures and in quantitative data such as number and the percentages of certain figure of training program and trainers, and trainees. Also because the current evaluation outcome out of data and not included data about the long 
terms impacts of training in the attended training and organization performance. This finding is parallel to the findings of Werner and DeSimone (2009), as they claimed that the definition of evaluation hey justify that "descriptive information provides a picture of what is happening or has happened, whereas judgmental information communicates some opinion or belief about what has happened" (p.198)

\subsection{Recommendations for improving the implementation current evaluation}

4.2.1 Activate the school context roles (Theme 1)

As stated from almost the respondents interviewed were highly concerned to improve the current practice of evaluation training programs of ES through activation of the school role, and based to their views in terms of evaluating the long-term levels. The participant emphasized that this could achieved within the ES visits to the school, since they have done most of their duties in the school

\subsubsection{Applying new or practical evaluation approaches (Theme 2)}

The second type of recommendations encourage the trend to use more the modern, practical, and convincing evaluation methods in terms of training program evaluation, for example, invest in technology such as the internet by utilizing online evaluation of the training programs. In their respondents views this can get by employed the internet as modern method in evaluation training program purpose. In their views this helpful way since of the widely users of the internet and it could be helpful whether it utilize in evaluation training programs purpose, also its able to keep in contact with the attended trainees at the work context, and it can less the cost of evaluation requirements...... Also the participant DS claimed that currently the overall implementation of the current evaluation process needs to be by run through an independent administrative institution or organization. In DS opinion this will assist in avoiding overlapping between the evaluators in the work context, and avoid many factors that affected in carry out evaluation.

\subsubsection{Develop the qualification of the implementation evaluation (Theme 3)}

The TE suggest that the ministry need to improve the current practice of evaluation training programs of ES and claimed that the number of evaluation employees presently needs to be increased, also need to establish more of evaluation training programs administrative sections, thus to cover all the implementation evaluation process of all the ES subject disciplines. Also they need to be more qualified in evaluation training field by increasing their experience through providing special courses in the field. This finding is in line with the findings of Eseryel (2002) as stated that there is lack of expertise of training designers in evaluation (p. 9). This finding is similar to the findings of Werner and DeSimone (2006) who asserted that the HRD professionals should have some required competencies and be able to carry out certain roles to ensure effective programs in an organization.

Finally, the findings regarding recommendation and suggestions are supported and in line with many findings in Oman local context. Studies show that the current evaluation process of training program need to develop, likewise, Al Khalil (2003); Al Hanshi (2004); Al Nabhani (2007); and Al Amri (2008), all these studies stated that the existing evaluation of training program by the MOE still not satisfactory, there are shortcomings in evaluating training results in the current MOE training programs, and there is limited and lack in training quality in both public and private sectors in Oman.

5.0 Conclusion 
Overall study findings showed the participants' view that there are many limitations in the current evaluation process, and these disadvantages could be overcome with the suitable recommendations given by participants as discussed in this study. It was evident that major changes are required in all the evaluation phases, especially upgrading of current skills in evaluation, a more systematic approach and usage of new methods for collecting and analyzing data for evaluation purposes and that an independent body must be set up to undertake ES training program evaluation to ensure objectivity of results.

Finally this study concluded that the ministry must take more action to reach high level in achieving the target evaluation of the training program of ES.

\section{References}

Al-Amri, A. M. A. (2008). A suggested agenda for the technical duties carried out by educational supervisors in the Sultanate of Oman in the light of the existing global trends. Unpublished $\mathrm{Ph}$. D thesis, Arab States University.

Al-Athari, A., \& Zairi, M. (2002). Training evaluation: an empirical study in Kuwait. Journal of European Industrial Training, 26(5), 241-251.

Al-Hanasi, M. (2004). An investigation into quality of training on the civil service units in the Sultanate of Oman. Unpublished master dissertation, Sheffield Hallam University.

Al-Hatmi, F. K. H. (2009). How effective is ICDL training for Omani teacher. Unpublished master dissertation, University of Manchester, Manchester.

Al-Khalili, S.(2003). Evaluation of training for Omani civilian employees. Unpublished Master Dissertation, Leicester University.

Al-Nabhani, M. B. M. (2007). Developing the education system in the Sultanate of Oman through implementing total quality management: The Ministry of Education Central Headquarters: A case study. Unpublished Ph. D thesis, University of Glasgow, Glasgow.

Aminuddin, M.(2001).Effective training in Malaysian organizations. Kuala Lumpur: McGraw-Hill.

Bramley, P. (1991). Evaluating training effectiveness: Translating theory into practice. London, UK: McGraw-Hill.

Brinkerhoff, R. O. (1987). Achieving results from training: How to evaluate human resource development to strengthen programs and increase impact. San Francisco, CA:Jossey-Bass.

Eseryel, D. (2002). Approaches to evaluation of training: Theory \&practice. Educational Technology \& Society, 5(2).

Galanou, E., \&Priporas, C.-V.(2009).A model for evaluating the effectiveness of middle managers' training courses: Evidence from a major banking organization in Greece. International Journal of training and development, 13(4), 221-246.

Goldstein, I. L., \& Ford, J. K. (2002).Training in organizations: Needs assessment, development, and evaluation (4th ed.). Belmont, CA: Wads worth.

Green, D. T. (2004).Corporate training programs: A study of the Kirkpatrick-Phillips model at Electronic Data System. Unpublished Ph.D thesis, Capella University, Minnesota.

Junaidah, Hashim. (2006). Training in organisations. Petaling Jaya: Pearson Malays ia.

Kirkpatrick, D. L. (2006).Evaluating training programs: The four levels (3rd ed.). San Francisco, CA: Berrett-Koehler.

Lingham, T., Richley, B., \&Rezania, D. (2006). An evaluation system for training programs: A case study using a four-phase approach. Career Development International, 11(4), 334-351.

Marshall, C., \&Rossman, G. B. (2006).Designing qualitative research (4th ed.). Thousand Oaks, CA: Sage. 
Phillips, J. J. (1997). Handbook of training evaluation and measurement methods (3rd ed.). Houston, TX: Gulf Publishing.

Phillips, J. J., \& Stone, R. D. (2002). How to measure training results. New York, NY: McGraw-Hill.

Phillips, P. P. (2003). Training evaluation in the public sector. Unpublished Ph.D dissertation, The University of Southern Mississippi.

Rae, L. (1999). Using evaluation in training and development. London, UK: Kogan Page.

Russ-Eft, D., \& Preskill, H. (2001). Evaluation in organizations: A systematic approach to enhancing learning, performance, and change. Cambridge, MA: Perseus.

Sims, R. R. (1993). Evaluating public sector training programs. Public Personnel Management, 22(4), 591-615.

Smith, E.(2002).Theory and practice: The contribution of off-the-job training to the development of apprentices and trainees. Journal of Vocational Education and Training, 54(3),431-456.

Stufflebeam, D. L., \&Shinkfield, A. J. (2007). Evaluation theory, models, \& applications.San Francisco, CA:Jossey-Bass.

Sultanate of Oman, Ministry of National Economic [ElectronicVersion].Vision for Oman's Economy: Oman 2020. Retrieved from MONE portal.

Sultanate of Oman, Ministry of Education.(2004a).National report on quality education in Oman. Muscat, Oman: Author.

Sultanate of Oman, Ministry of Education.(2004b). The philosophy and objectives of education in the Sultanate of Oman. Muscat, Oman: Author.

Sultanate of Oman, Ministry of Education. (2006).From access to success: Education for all (EFA) in the Sultanate of Oman 1970-2005. Muscat, Oman: Author.

Wang, G. G., \& Wilcox, D. (2006, November). Training evaluation: Knowing more than is practiced. Advances in Developing Human Resources, 18(4), 528-539.

Werner, J. M., \& DeSimone, R. L. (2009). Human resource development. OH: South-Western Cengage Learning.

Wills, M. (1993). Managing the training process: Putting the basics into practice. London, UK: McGraw-Hill. 